\title{
Zn speciation in a soil contaminated by the deposition of a dredged sediment by synchrotron $x$-ray techniques
}

Isaure Marie-Pierre ${ }^{1,2,}{ }^{*}$, Manceau Alain ${ }^{1}$, Laboudigue Agnès ${ }^{2}$, Nobumichi Tamura ${ }^{3}$, Marcus Matthew A. ${ }^{3}$

${ }^{1}$ Environmental Geochemistry Group, LGIT- Maison des Géosciences, University J. Fourier and CNRS, 38041 Grenoble cedex 9, France

${ }^{2}$ Centre National de Recherche sur les Sites et Sols Pollués, 930 Boulevard Lahure, BP537, 59505 Douai cedex, France

${ }^{3}$ Advanced Light Source, Lawrence Berkeley National Laboratory, One Cyclotron Road, Berkeley, California 94720, USA

* Present address: Isaure M.P., CEA-Grenoble, DRT/DTEN/SAT, 17 rue des Martyrs, 38054 Grenoble cedex 9; Phone: 33 (0)4 387838 48; Fax: 33 (0)4 387851 34;

e-mail: marie-pierre.isaure@cea.fr 


\begin{abstract}
The nature and proportion of $\mathrm{Zn}$ species present in an agricultural soil overlaid by a dredged contaminated sediment have been untangled by the novel combination of three non-invasive synchrotron-based $\mathrm{x}$ ray techniques: $x$-ray microfluorescence $(\mu \mathrm{SXRF})$, microdiffraction $(\mu \mathrm{XRD})$, and absorption spectroscopy (EXAFS). One primary (franklinite) and two secondary (phyllomanganate and phyllosilicate) Zn-containing minerals were identified in the initial soil, and another primary $(\mathrm{ZnS})$ and a new secondary (Fe-(oxyhydr)oxide) $\mathrm{Zn}$ species in the covered soil. The quantitative analysis of EXAFS spectra recorded on bulk samples indicated that $\mathrm{ZnS}$ and $\mathrm{Zn}-\mathrm{Fe}$ (oxyhydr)oxides amounted to $71 \pm 10 \%$ and $27 \pm 10 \%$, respectively, and the other $\mathrm{Zn}$ species to less than $10 \%$. The two new $\mathrm{Zn}$ species found in the covered soil result from the gravitational migration of $\mathrm{ZnS}$ particles initially present in the sediment, and from their further oxidative dissolution and fixation of leached $\mathrm{Zn}$ on Fe (oxyhydr)oxides.
\end{abstract}

\title{
1. INTRODUCTION
}

Dredging operations carried out to maintain the depth of navigational units worldwide generate high volume of sediments, which are generally deposited on soils along banks. In industrialized regions, these sediments are contaminated with heavy metals, and consequently, these deposits constitute an important source of pollutants for the surrounding environment, and specifically the underlying soil. Since metals solubility and mobility are predominantly controlled by their interactions with soil constituents, the knowledge of the molecular form of metals in solid phases is a key issue to assess the chemical risk and predict the effect of a variation of physico-chemical parameters on the fate of metals. Among the methods available to determine the speciation of metals in the solid phase of soils, x-ray absorption spectroscopy (EXAFS) is arguably the most efficient [1]. However, the existence of multiple species is a real limitation, and this drawback is generally overcome by fractionating the soil to reduce its heterogeneity in isolating or removing some metal species [2,3]. Still, this approach is not fully satisfying because it has been found that chemical and physical treatments can cause artefacts in modifying the very chemistry one is trying to probe [4]. In this work, we used the new combination of three synchrotronbased $x$-ray techniques, i.e., $x$-ray microfluorescence $(\mu \mathrm{SXRF})$, microdiffraction $(\mu \mathrm{XRD})$, and absorption spectroscopy ( $\mu$ EXAFS and bulk EXAFS), as discussed by Manceau, et. al. [5], to speciate $\mathrm{Zn}$ in a soil impacted by the deposition of a dredged sediment. $\mu$ SXRF was used to map the distribution of elements, $\mu \mathrm{XRD}$ enabled the identification of nanoscale particles, and $\mu$ EXAFS allowed one to identify the mechanism of metal binding by the host phases (i.e., identify metal species). Then, the proportion of each metal species in the bulk was determined by analyzing the unknown multicomponent bulk EXAFS spectrum as a linear combination of component spectra corresponding to single metal species.

\section{MATERIALS AND METHODS}

Forty cubic meters of a sediment were dredged nearby a $\mathrm{Zn}$ smelter in Northern France ([Zn] $=6600$ $\mathrm{ppm}$ ), and deposited as a $40 \mathrm{~cm}$ thick layer on a non-polluted agricultural soil in July 1997. Originally, Zn was mainly speciated as $\mathrm{ZnS}$ and $\mathrm{Zn}-\mathrm{Fe}$ (oxyhydr)oxides [2]. After 15 months of deposition, the $\mathrm{Zn}$ content amounted to $260 \mathrm{ppm}$ in the $<50 \mu \mathrm{m}$ fraction of the underlying soil compared to a geochemical background of $50 \mathrm{ppm}$. The $<50 \mu \mathrm{m}$ fraction represented $90 \%$ of the mass of the soil and was considered as representative of the bulk soil. The $<0.2 \mu \mathrm{m}$ fine fractions of the initial and affected soil were also 
extracted for powder and polarized-EXAFS (P-EXAFS) measurements. Finally, impregnated $30 \mu \mathrm{m}$-thick thin sections of the unperturbed soil before and after treatment were prepared for $\mathrm{X}$-ray microscopic investigations.

$\mu \mathrm{SXRF}$ and $\mu$ EXAFS measurements were performed on beamline 10.3.2 at the Advanced Light Source (ALS, Berkeley, USA), $\mu$ XRD on beamline 7.3.3 at the ALS, and P-EXAFS and bulk EXAFS on beamline FAME at the European Synchrotron Radiation Facility (ESRF, Grenoble, France). Fe, Mn and Zn $\mu$ SRXF maps were obtained by scanning thin-sections with a beam size of $16 \mu \mathrm{m} \times 5 \mu \mathrm{m}$ while recording the X-ray fluorescence with a 7-element Ge solid-state detector. Zn-K edge $\mu$ EXAFS spectra were then collected in fluorescence mode on various regions-of-interests. Point $\mu$ XRD patterns were collected on the same thin-sections using a CCD camera [5]. Fluorescence-yield Zn K-edge P-EXAFS measurements were carried out on self-supporting films from the $<0.2 \mu \mathrm{m}$ fraction at incident angles between the electric field vector and the film plane of $\alpha=0^{\circ}, 35^{\circ}$ and $80^{\circ}$ [6], and bulk EXAFS measurements were performed on pressed pellets from the $<50 \mu \mathrm{m}$ soil fraction. EXAFS spectra were compared to Zn-reference EXAFS spectra and least-squares fitted with linear combination of references. The fit criterion was estimated by $\mathrm{R}=\Sigma\left|\left(\mathrm{k}^{3} \chi_{\exp }-\mathrm{k}^{3} \chi_{\text {model }}\right)\right| / \Sigma\left|\mathrm{k}^{3} \chi_{\exp }\right|$ and the addition of a new component was considered meaningful if the $\mathrm{R}$ decrease amounted to at least $20 \%$.

\section{RESULTS AND DISCUSSION}

\subsection{Speciation of $\mathrm{Zn}$ in the uncontaminated soil before the deposition of the sediment}

\subsection{1 $\mu S X R F$ and $\mu X R D$}

Several regions were examined by $\mu \mathrm{SXRF}$ and the mineralogy and crystal chemistry of $\mathrm{Zn}$ is completely represented by the region presented in Figure 1. This map shows that the soil is highly heterogeneous at the micrometer scale, containing distinct areas of concentrated Fe, Mn, and $\mathrm{Zn}$. Three $\mathrm{Zn}$ species could be inferred from this analysis: $\mathrm{Zn}$ in association with $\mathrm{Mn}, \mathrm{Zn}$ in grains ('hot spots'), and $\mathrm{Zn}$ in diffuse concentration throughout the fine matrix.
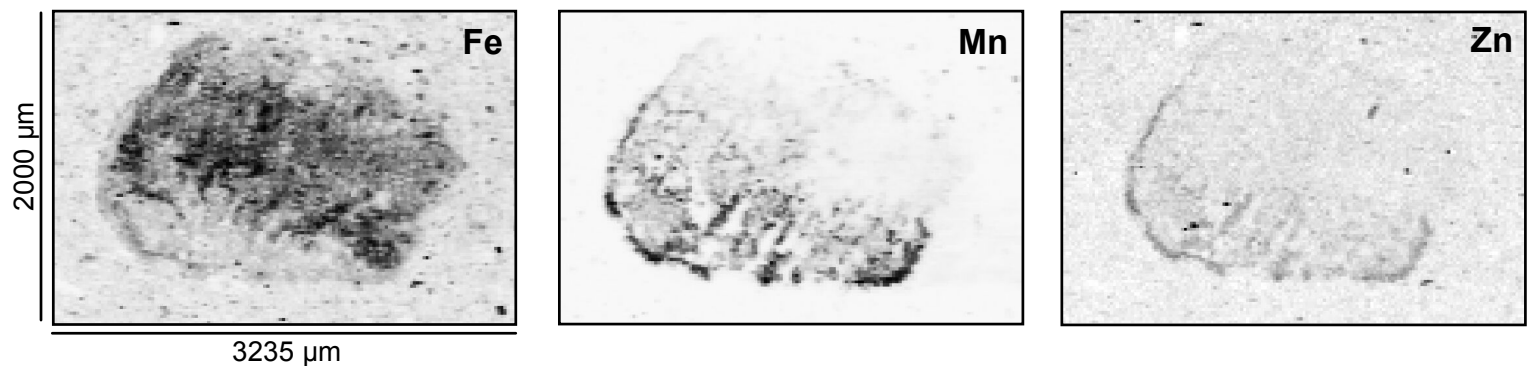

Figure 1. Gray-scale $\mu \mathrm{SXRF}$ maps in negative contrast showing the distribution of Fe, Mn and $\mathrm{Zn}$ in the uncontaminated soil. The Fe and $\mathrm{Mn}$ maps were collected at $10 \mathrm{keV}$, and the $\mathrm{Zn}$ map was obtained by subtracting the normalized fluorescence signal recorded $50 \mathrm{eV}$ above and below the $\mathrm{Zn} \mathrm{K}$-edge to eliminate any noise. Beam size: $16 \mu \mathrm{m}$ x $5 \mu \mathrm{m}$; step sized: $20 \mu \mathrm{m} \times$ $20 \mu \mathrm{m}$; dwell time: $400 \mathrm{~ms} /$ point.

In addition to minerals classically encountered in soils, such as quartz, calcite, microcline, albite, and dioctahedral phyllosilicates, $\mu$ XRD identified vernadite $\left(\delta \mathrm{MnO}_{2}\right)$, a randomly-stacked phyllomanganate, in $\mathrm{Mn}$-rich areas, and poorly-crystalline Fe (oxyhydr)oxides (likely feroxyhite, $\delta \mathrm{FeOOH}$ ) in Fe-rich areas. No Zn precipitates were detected.

\subsection{2 $\mu$ EXAFS, P-EXAFS and bulk EXAFS spectroscopy}

Zn-sorbed birnessite and franklinite $\left(\mathrm{ZnFe}_{2} \mathrm{O}_{4}\right)$ were firmly identified by $\mu$ EXAFS spectroscopy in Mnrich areas and $\mathrm{Zn}$ hot spots (Fig. 2). The presence of $\mathrm{Zn}$ layered compounds in the fine matrix was established by P-EXAFS, which showed a strong angular dependence of the measured signal with $\alpha$ angle. The $\alpha=35^{\circ}$ P-EXAFS spectrum (i.e., powder spectrum) was correctly fitted with Zn-kerolite, a trioctraedral smectite used as proxy for Zn-containing phyllosilicate (Fig. 2c). The frequency and 
amplitude of the EXAFS spectrum for the $<50 \mu \mathrm{m}$ fraction resembles the $<0.2 \mu \mathrm{m}$ fraction (Fig. $2 \mathrm{~d}$ ), and the spectral simulation with two components (Zn-kerolite + Zn-sorbed birnessite or franklinite) did not result in a better spectral match. This analysis indicates that $\mathrm{Zn}$ is overwhelmingly speciated as phyllosilicate in the bulk uncontaminated soil and, hence, that franklinite and Zn-birnessite are minor species.
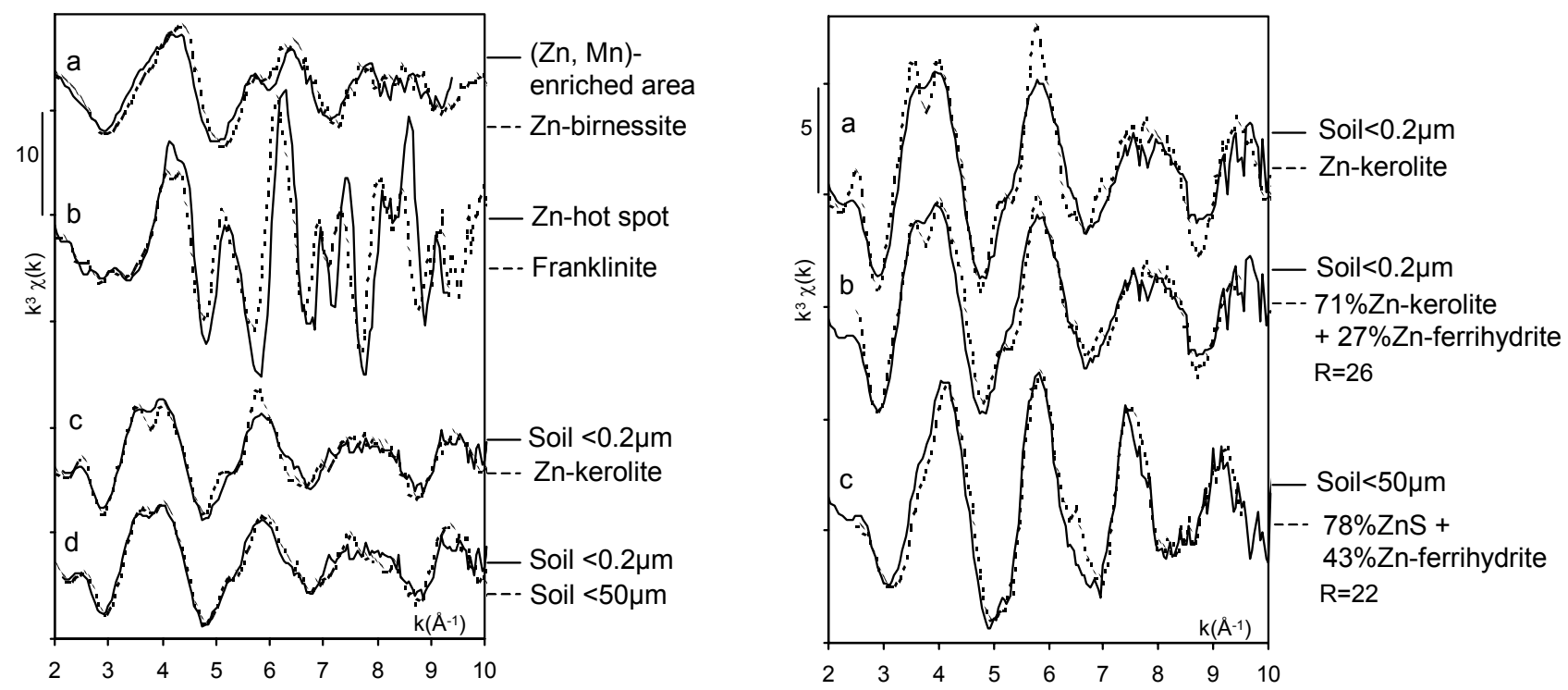

Figure 2: Uncontaminated soil before the deposition of the Figure 4: Soil contaminated after the deposition of dredged dredged sediment. (a,b) Zn K-edge $\mu$ EXAFS spectra collected sediment. (a) Zn K-edge $\alpha=35^{\circ} \mathrm{P}-\mathrm{EXAFS}$ spectrum collected in selected points; (c) $\alpha=35^{\circ} \mathrm{P}$-EXAFS spectrum collected on on the $<0.2 \mu \mathrm{m}$ fraction compared to Zn-kerolite, (b) twothe $<0.2 \mu \mathrm{m}$ fraction compared to Zn-kerolite, (d) $\alpha=35^{\circ} \mathrm{P}$ - component fit of the $<0.2 \mu \mathrm{m}$ fraction, (c) two-component fit EXAFS spectrum for the $<0.2 \mu \mathrm{m}$ fraction compared to the of the $<50 \mu \mathrm{m}$ fraction.

EXAFS spectrum for the $<50 \mu \mathrm{m}$ fraction.

\subsection{Speciation of $\mathrm{Zn}$ in the soil contaminated after the deposition of sediment}

\subsection{1 $\mu S X R F$ and $\mu X R D$}

The element map presented in Figure 3 shows the occurrence of a Zn-containing slag $(\sim 1500 \mu \mathrm{m}$ sized) in the upper left side of the mapped area. Similar coarse anthropogenic debris were observed in the sediment [2], and their presence in the underlying soil results from gravitational transfer. Four $\mathrm{Zn}$ forms or associations are visible on this map: $\mathrm{Zn}$ on the rim of the slag material, $\mathrm{Zn}$ bound to $\mathrm{Mn}$ in individual grains, $\mathrm{Zn}$-rich grains, and $\mathrm{Zn}$ and Fe throughout the fine soil matrix.
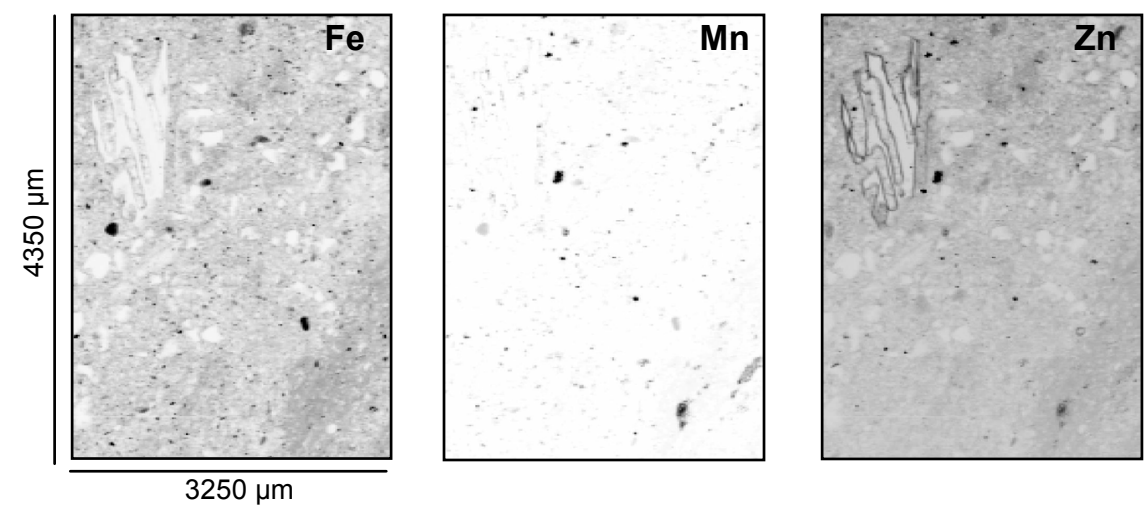

Figure 3. Gray-scale $\mu \mathrm{SXRF}$ maps in negative contrast showing the distribution of Fe, Mn and $\mathrm{Zn}$ in the soil contaminated after the deposition of the sediment. Elemental maps were collected at $10 \mathrm{keV}$. Since the concentration of $\mathrm{Zn}$ in this sample is high, the noise level of the $\mathrm{Zn}$ map is very low and all shaded areas indicate the presence of $\mathrm{Zn}$. Beam size: $16 \mu \mathrm{m} \times 5 \mu \mathrm{m}$; step sized: $20 \mu \mathrm{m}$ x $15 \mu \mathrm{m}$; dwell time: $600 \mu \mathrm{ms} /$ point. 
$\mu X R D$ patterns recorded on the Mn grains identified vernadite. In the soil matrix, diffraction peaks from vernadite decreased while those of ferrihydrite and/or feroxyhite were detected systematically. No $\mathrm{Zn}$ precipitates or Zn-containing primary minerals were identified by this technique.

3.2.2 $\mu$ EXAFS, P-EXAFS and bulk EXAFS spectroscopy

$\mu$ EXAFS spectra collected on individual $\mathrm{Fe}$ and $\mathrm{Mn}$ grains allowed the identification of franklinite and Zn-phyllomanganate, as in the initial soil, and kerolite-like Zn-phyllosilicate was also detected by PEXAFS spectroscopy (Fig. 4a). However, in contrast to the initial soil, a good match for the $<0.2 \mu \mathrm{m}$ spectrum required the addition of two-component spectra, Zn-kerolite and Zn-sorbed ferrihydrite in proportion of $71 \pm 10 \%$ and $27 \pm 10 \%$, respectively (Fig. 4b). The EXAFS signal from the bulk soil was satisfactorily reconstructed by a mixture consisting of $78 \pm 10 \% \mathrm{ZnS}$ and $43 \pm 10 \% \mathrm{Zn}$-sorbed ferrihydrite (Fig. 4c), indicating that the Zn-phyllosilicate and Zn-birnessite species are not quantitatively of paramount importance in the Zn-affected soil. This finding stands in strong contrast with results from the initial soil, and can be rationalized by the per descensum migration of $\mathrm{ZnS}$ slag material from the sediment and the sorption of $\mathrm{Zn}$ released by the oxidative dissolution of sphalerite on poorly crystallized Fe (oxyhydr)oxides.

\section{CONCLUSION}

$\mathrm{Zn}$ speciation in a soil contaminated by the deposition of a $\mathrm{Zn}$-containing dredged sediment was successfully determined and quantified by collectively applying x-ray fluorescence, diffraction, and absorption. In the untreated soil, $\mathrm{Zn}$ is predominantly speciated as phyllosilicate, and secondarily as phyllomanganate and franklinite. In the treated soil, $\mathrm{Zn}$ is mainly present as sphalerite and $\mathrm{Zn}-\mathrm{Fe}$ (oxyhydr)oxides, and to a lesser extent as Zn-phyllosilicate, Zn-phyllomanganate, and franklinite. ZnS grains originate from the sediment, and their oxidative weathering is responsible for the leaching and fixation of $\mathrm{Zn}$ on $\mathrm{Fe}$ (oxyhydr)oxides. This work illustrates the potential of the complementary use of $\mu \mathrm{SXRF}, \mu \mathrm{XRD}$ and $\mu \mathrm{EXAFS}$ techniques as a quantitative analytical tool for speciation of dilute multicomponent environmental materials not easily attainable with conventional methods.

\section{Acknowledgments}

We are grateful to J.L. Hazemann, O. Proux and J.J. Menthonnex on FAME for their technical assistance, and to the ESRF and the ALS for the provision of beamtime. We also acknowledge the LESTS at IRSN in Fontenay-aux-roses, France, for preliminary SEM-EDS measurements. This research was supported by European FEDER funds.

\section{References}

[1] Manceau A., Lanson B., Schlegel M., Hargé J.C., Musso M., Eybert-Bérard L., Hazemann J.L., Chateigner D., Lamble G., Am. J. of Sci. 300 (2000) 289-343.

[2] Isaure M.P., Laboudigue A., Manceau A., Sarret G., Tiffreau C., Trocellier P., Lamble G., Hazemann J.L., Chateigner D., Geochim. Cosmochim. Acta 66 (2002) 1549-1567.

[3] Scheinost A.C., Kretzschmar R., Pfister S., Roberts D.R., Environ. Sci. Technol. 36 (2002) 50215028.

[4] Ostergren J.D., Brown G.E. Jr., Parks G.A., Tingle T.N., Environ. Sci. Technol. 33 (1999) 1627-1636.

[5] Manceau, A., Marcus, M.A., Tamura, N., in Applications of Synchrotron Radiation in LowTemperature Geochemistry and Environmental Science, Fenter P., Rivers M., Sturchio N.C., Sutton S. Eds, Reviews in Mineralogy and Geochemistry (Mineralogical Society of America, Washington, DC., 2002), 49 341-428.

[6] Manceau A., Schlegel M., Chateigner D., Lanson B., Bartoli C., Gates W.P., in Synchrotron X-ray methods in clay science, Schulze D., Bertsch P., Stucki J. Eds (Clay Mineral Society of America, Boulder, Co., 1999) 9 68-114. 